\title{
SIAN FIELDING
}

\section{The value of cranial computed tomography in old age psychiatry: a review of the results of 178 consecutive scans}

\author{
AIMS AND METHOD \\ To assess the value of computed \\ tomography (CT) in patients \\ presenting to an old age psychiatry \\ service over a 2-year period, and to \\ evaluate a set of clinical prediction \\ rules and the recommendations of \\ the Royal College of Psychiatrists on \\ the selection of patients for scanning. A \\ retrospective review of the reports \\ of 178 consecutive scans and case \\ note reviews was carried out.
}

\author{
RESULTS \\ Four scan reports (2.3\%) suggested \\ potentially reversible causes (PRCs) \\ of dementia. Of these, only two \\ showed unequivocal organic brain \\ lesions. Both of these patients were \\ identified by each of the prediction \\ rules tested. There was a high \\ incidence of small vessel disease \\ $(32.8 \%)$ and infarcts (11.9\%).
}

\begin{abstract}
CLINICAL IMPLICATIONS
$\mathrm{CT}$ is a low-yield investigation in terms of identifying patients with PRCs of dementia. The tested clinical prediction rules appear sensitive in detection of PRCs. CT may demonstrate unsuspected cerebrovascular disease.
\end{abstract}

Dementia presents a major public health challenge to the developed world (Ernst, 1994). Effective evaluation and early diagnosis of dementia might lead to the identification of potentially reversible organic causes. Therefore, investigation and diagnosis helps to identify patients who might benefit from cholinesterase inhibitors or, in the case of vascular dementia, from antiplatelet medication.

A wide variety of imaging strategies have been reported in the evaluation of dementia (Jagust, 2000; Frisoni, 2000). Despite this, computed tomography (CT) remains the most widely available modality, and therefore the mainstay of imaging for most patients in the UK. Imaging in dementia has two aims: first, to identify the small proportion of patients who have a potentially reversible cause (PRC) for their dementia, such as subdural haematomas, tumours and normal pressure hydrocephalus. A second aim of imaging is to assist in the diagnosis and help to establish the subtype of dementia. There is some evidence that CT might be useful in this respect, particularly when combined with hexylmethylpropylenamine oxime single photon emission computed tomography (HMPAO SPECT) (Jobst et al, 1998).

Previous investigation into the prevalence of treatable pathology in patients with cognitive impairment has shown a prevalence of underlying organic lesions in the order of $9 \%$, although only between $1.5 \%$ and $3 \%$ have reversible pathology (Clarfield, 1988; Weytingh, 1995). While the prevalence of such pathology is low, it is very difficult to predict prior to scanning which patients will have organic brain lesions. A review of the published clinical prediction rules (Gifford et al, 2000) revealed that none of the published recommendations have a consistently high sensitivity and specificity. The clinical prediction rule proposed by Dietch (1983) suggests a series of 11 criteria for identifying patients unlikely to benefit from cranial CT (Table 1). By applying this approach, PRCs are predicted with a sensitivity of

\begin{tabular}{|c|c|}
\hline Reference & Recommendation \\
\hline Dietch (1983) & $\begin{array}{l}\text { Scan all patients unless all of the following } \\
\text { criteria are met: } \\
\text { Dementia for at least } 1 \text { month } \\
\text { No head trauma in the week proceeding } \\
\text { change in mental state } \\
\text { Gradual onset (not less than } 48 \text { h) of } \\
\text { changes in mental state } \\
\text { No history of malignant tumour } \\
\text { No history of cerebrovascular accident } \\
\text { No history of seizures } \\
\text { No history of urinary incontinence } \\
\text { No focal cerebral signs } \\
\text { No papilloedema } \\
\text { No visual field defects } \\
\text { No apraxia or ataxia of gait }\end{array}$ \\
\hline $\begin{array}{l}\text { Royal College } \\
\text { of Psychiatrists } \\
\text { (1995) }\end{array}$ & $\begin{array}{l}\text { Scan all patients unless: } \\
\text { History is typical } \\
\text { OR history greater than } 1 \text { year }\end{array}$ \\
\hline
\end{tabular}

between $87.5 \%$ (Martin et al, 1987) and 100\% (Dietch, 1983). The specificity is between $37.2 \%$ (Martin et al, 1987) and $52.9 \%$ (Dietch, 1983). A further study demonstrated a sensitivity of $95.2 \%$ for the Dietch criteriafor the prediction of PRCs in a group of 83 patients known to have potentially reversible pathology, but presenting with cognitive impairment (Alexander et al, 1995).

The Royal College of Psychiatrists (1995) published a consensus statement into the assessment of elderly patients with suspected cognitive impairment. The guidelines included a consensus view as to which patients should be referred for imaging (Table 1). Applying these guidelines to 155 consecutive CT scan referrals, Branton (1999) found that all 10 of the patients with PRCs were 
Table 2. Report from 177 consecutive cranial computed tomography scans

original papers

\begin{tabular}{|lcc}
\hline Scan finding & \multicolumn{2}{c}{$\begin{array}{l}\text { \% with this } \\
\text { finding }\end{array}$} \\
\hline Cerebral atrophy & 118 & 66.7 \\
Small vessel disease & 58 & 32.8 \\
Infarcts (specific vascular territory) & 21 & 11.9 \\
Potentially reversible cause of dementia & 4 & 2.3 \\
\hline
\end{tabular}

correctly predicted by the College guidelines. The prevalence of PRCs in this study was $7.8 \%$.

There remains much controversy about the selection of patients for imaging, and some authors suggest that all patients with dementia should be imaged (Cummings, 2000). Because of the uncertainties involved, referral patterns for imaging may vary. The prevalence of PRCs in a particular clinical setting has a role in the rational selection of patients for imaging.

\section{Method}

This study was a retrospective analysis of all referrals for cranial CT by old age psychiatrists based in Maindiff Court Hospital, Abergavenny, South Wales. There are two consultants in old age psychiatry based at this hospital. The catchment area of the service includes the northeast parts of the Welsh Valleys including Tredegar and Blackwood, as well as a more rural area stretching between Abergavenny and Monmouth. Patients from these teams are sent to either Nevill Hall Hospital in Abergavenny or the Royal Gwent Hospital in Newport for CT. Patients were identified from the computer databases of the radiology departments of the two hospitals (Radiological Information System). Scans were performed at both hospitals on Somatom plus 4 helical CT scanners (Siemens)
From the computer database, the following data were ascertained: the team referring the patient, age, sex, patient location (in-patient or out-patient) and scan report. The scan report was analysed and note was made of whether or not there was any mention of atrophy, generalised low attenuation within the white matter (leukomalacia) or infarcts in specific vascular territories, and whether there was any PRC for dementia. For the patients with PRCs, a retrospective review of the case notes was undertaken. This was performed using a proforma, identifying whether or not points on the Dietch criteria or the College criteria were present in the history or examination. Note was also taken of the effect the scan had on patient management and the eventual outcome of the case.

\section{Results}

A total of 178 patients were referred for cranial CT during the study period. One patient was unable to cooperate with the scan and hence, results were available for 177 patients. One hundred and seventy-two scans were performed without contrast, 5 scans were performed pre- and post-intravenous contrast. The mean age of the scanned patients was 77.53 years (s.d. 7.9), and 118 female patients and 59 male patients were scanned. Sixty-six patients were in-patients and 112 were outpatients.

Table 2 summarises the results of 177 CT scans. The majority of scan reports made some reference to cerebral atrophy. There was a fairly high prevalence of both infarcts (11.9\%) and small vessel disease (32.8\%).

Four scans showed potentially significant organic pathology (2.3\%). The scan findings for these patients are summarised in Table 3. All four of these patients had features as set out by the Dietch criteria. Two of the four patients had indications for scanning as defined by the College criteria. Only in one case (patient 1) was treatment for organic pathology (steroids) instigated following the

Table 3. Potentially reversible causes of dementia

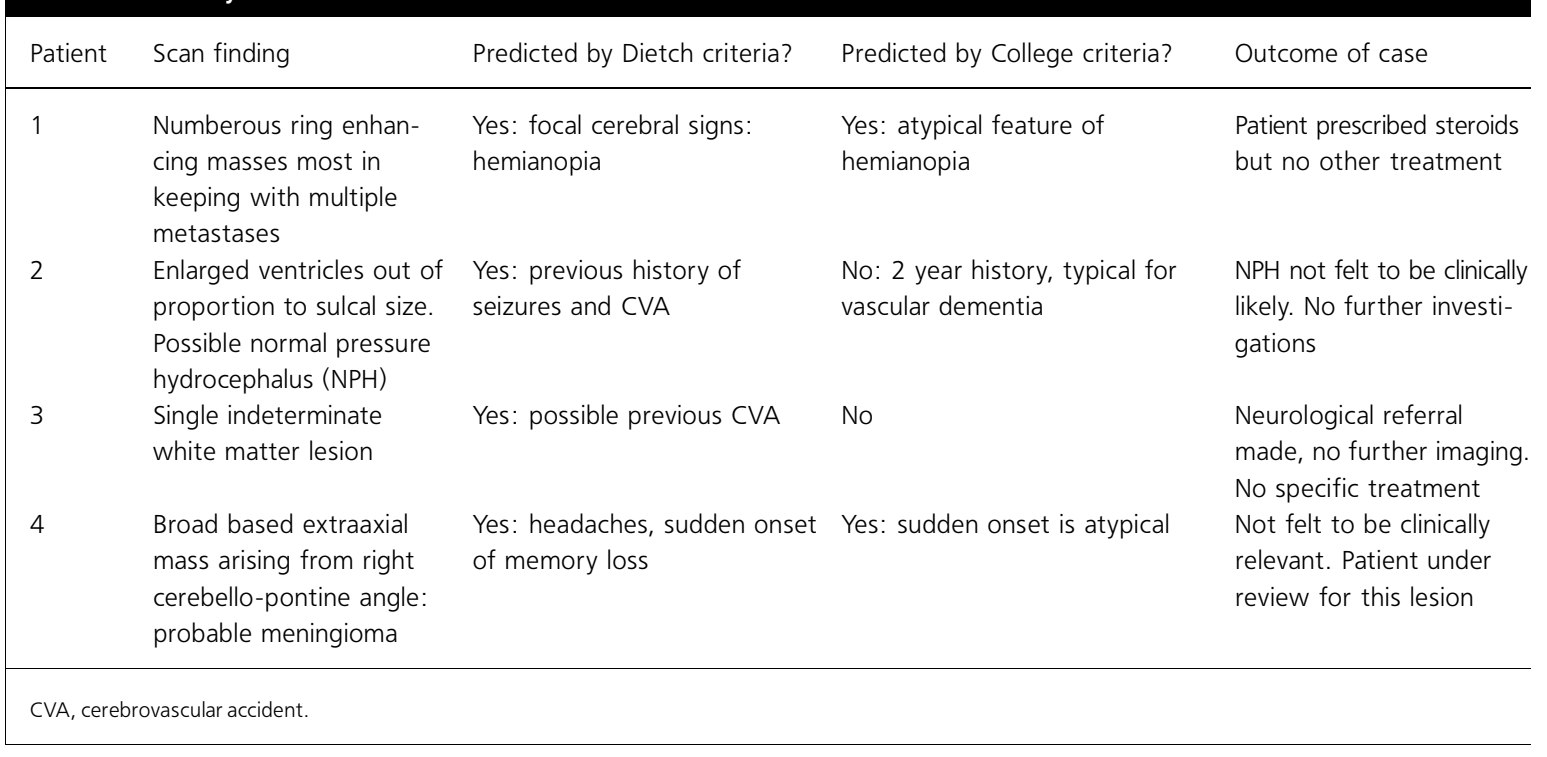


scan, and there were no cases of wholly reversible pathology.

\section{Discussion}

This study demonstrates a relatively low prevalence of PRCs of dementia (2.3\%). Most of the literature on the prevalence of PRCs comes from the 1980s. For example, Clarfield reported a $13.7 \%$ prevalence of PRCs in 1988 .

The only recent report from the UK literature was reviewing scans performed between 1994 and 1996 (Branton, 1999), and this demonstrated a prevalence of $7.8 \%$. The apparent decreasing prevalence of PRCs might reflect a lower threshold in requesting cranial CT as this investigation becomes more widely and routinely available.

In this cohort, no patient had any wholly reversible cause for cognitive impairment identified by CT. The study thus confirms that the prevalence of truly reversible causes of dementia identified by cranial CT is, in fact, extremely low (Foster et al, 1999).

All four patients with a PRC were correctly identified by the Dietch criteria. The Royal College of Psychiatrists guidelines correctly predicted two patients with the most significant intracranial pathology, namely patient 1 with multiple cerebral metastases and patient 4 with a probable meningioma. The College guidelines would not have predicted patients 2 and 3, however - these patients had fairly marginal imaging abnormalities, one with an indeterminate white matter lesion not thought to be clinically significant and another with enlarged ventricles, but in whom normal pressure hydrocephalus was felt clinically unlikely. In neither of these two cases did the scan findings result in a management change and in both cases, the scan result was thought to be of doubtful overall significance. Therefore, they should not be taken as evidence of a lack of sensitivity of the College criteria. This study, therefore, adds validity to both of the assessed clinical prediction rules.

Three of the scanned patients (2,3 and 4) had abnormal CT reports raising the possibility of reversible organic pathology, but none of these patients had a treatment change resulting from the scan. It may be argued that the imaging findings in these cases are incidental and that the scans did not lead to any real benefit to the patients. In these cases, scanning adds cost to the management of the patient and generates more work, as well as provoking anxiety and uncertainty in the patient and their carers. Such problems are a wellrecognised drawback to widely applying sensitive diagnostic tests to large populations of patients.

A notable finding of this study is the high prevalence of evidence of small (32.6\%) and large (11.9\%) vessel cerebrovascular disease in our study population (Table 2). A real benefit of scanning, therefore, is to raise the possibility of vascular dementia. In this respect, cranial CT may well add to the management of patients with cognitive impairment.

\section{References}

ALEXANDER, E. M.,WAGNER, E. H., GIFFORD, D. R., HOLLOWAY, R. G. \& BUCHNER, D. M., et al (1995) Do VICKREY, M. D. (2000) Systematic surgical brain lesions present as isolated review of clinical prediction rules for dementia? A population based study. neuroimaging in the evaluation of Journal of the American Geriatric dementia. Archives of Internal Society, 43, 148-143. Medicine, 160, 2855-2862.

BRANTON,T. (1999) Use of computerized tomography by old age psychiatrists: an examination of criteria for investigation of cognitive impairment. International Journal of Geriatric Psychiatry, 14, 567-571.

CLARFIELD, A. M. (1988) The reversible dementias, do they reverse? Annals of Internal Medicine, 109, 476-486.

CUMMINGS, J. L. (2000) Neuroimaging in the dementia assessment: is it necessary? Journal of the American Geriatric Society, 48, 1345-1346.

DIETCH, J.T. (1983) Computerized tomographic scanning in cases of dementia. Western Journal of Medicine 138, 835-837.

ERNST, R. L. \& HAYT, J.W. (1994) The US economic and social costs of Alzheimer's disease relisted. American Journal of Public Health, 84, 1261-1264.

FRISONI, G. B. (2000) Structural imaging in the clinical diagnosis of Alzheimer's disease: problems and tools. Journal of Neurology, Neurosurgery and Psychiatry, 70, 711-718. JAGUST, W. J. (2000) Neuroimaging in dementia. Dementia, 18, 885-901.

JOBST, K. A., BARNETSON, L. P. D. \& SHEPSTONE, B. J., on behalf of the Oxford project to investigate memory and aging (1998) Accurate prediction of histologically confirmed Alzheimer's disease and the differential diagnosis of dementia: the use of the NINCDSADRDA and DSM-III-R criteria, SPECT, $X$-Ray CT, and Apo E4 in medial temporal lobe dementias. International Psychogeriatrics, 10, 271-302.

MARTIN, D. C., MILLER, J., KAPOOR,W., et al (1987) Clinical prediction rules for computed tomographic scanning in senile dementia. Archives of Internal Medicine, $147,77-80$

ROYAL COLLEGE OF PSYCHIATRISTS (1995) Consensus Statement on the Assessment of an Elderly Person with Suspected Cognitive Impairment by a Specialist Old Age Psychiatry Service (Council Report CR49). London: Royal College of Psychiatrists. WEYTINGH, M. D., BOSSUYT, P. M. \& VAN CREVEL, H. (1995) Reversible

FOSTER, G. R., SCOTT, D. A. \& PAYNE, S. dementia: more than $10 \%$ or less than (1999) The use of CTscanning in dementia: a systematic review. International Journal of Technology Assessment in Health Care, 15, 406-423. $1 \%$ ? A quantitative review. Journal of Neurology, 242, 466-471.

Sian Fielding Specialist Registrar, Old Age Psychiatry, Maindiff Court Hospital, Maindiff, Abergavenny, Wales (e-mail: pafielding@ukonline.co.uk) original

papers 